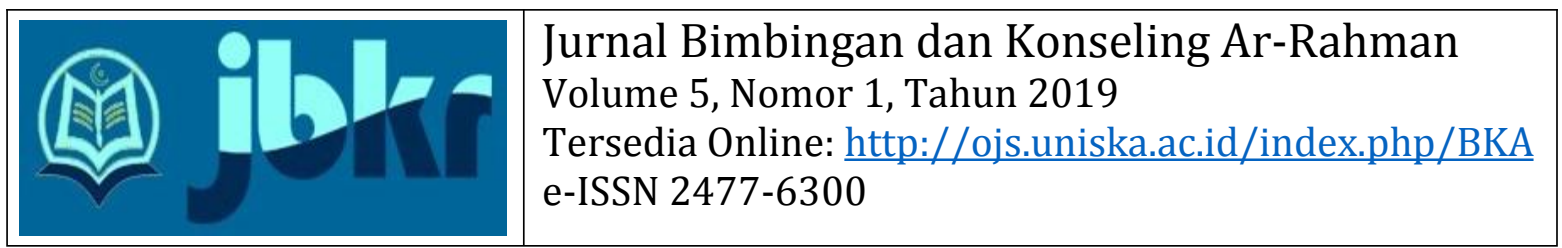

\title{
RASA INGIN TAHU REMAJA DITINJAU DARI KEINGINAN UNTUK MENGAKTUALISASIKAN DIRI DALAM RUANG LINGKUP SEKOLAH
}

\author{
Angeline Hosana Zefany Tarigan ${ }^{1}$, Indra Prapto Nugroho² \\ Program Studi Psikologi Fakultas Kedokteran, Universitas Sriwijaya \\ angelinetarigan@fk.unsri.ac.id, ipnugroho@fk.unsri.ac.id
}

\begin{abstract}
ABSTRAK
Remaja memiliki rasa ingin tahu yang besar. Keingintahuan ini dapat menyebabkan remaja semakin termotivasi untuk menjadi lebih baik daripada sebelumnya. Rasa ingin tahu pada remaja juga merupakan bagian dari usaha untuk menjadi bermakna tidak hanya bagi dirinya sendiri melainkan juga orang lain. Saat rasa ingin tahu remaja sudah terpenuhi, maka remaja akan terdorong untuk mengaktualisasikan dirinya. Hal ini merupakan bagian dari kebutuhan eksistensi dari remaja. Tujuan dari penelitian ini adalah untuk menjelaskan hubungan rasa ingin tahu dengan keinginan untuk mengaktualisasikan diri pada remaja. Penelitian ini merupakan penelitian kuantitatif korelasional dimana jumlah partisipan sebanyak 100 orang dengan menggunakan alat ukur Self-Actualization Activity Inventory (SAAI) dan Curiosity and Exploration Inventory. Teknik pengambilan sampel menggunakan simple purposive sampling. Hasil penelitian menunjukkan bahwa terdapat hubungan antara rasa ingin tahu dengan aktualisasi diri pada remaja dalam ruang lingkup sekolah $(r=0,581 ; p=0,000)$. Artinya semakin tinggi rasa ingin tahu maka semakin tinggi kemampuan siswa untuk mengaktualisasikan dirinya. Dari penelitian ini dapat disimpulkan bahwa terdapat hubungan yang signifikan antara rasa ingin tahu dengan keinginan untuk mengaktualisasikan diri pada remaja dalam ruang lingkup sekolah. Rasa ingin tahu yang besar menyebabkan individu berusaha mengumpulkan informasi baru dan penting untuk memaksimalkan potensi dalam diri sehingga mampu mengaktualisasikan dirinya.
\end{abstract}

Kata Kunci: rasa ingin tahu; aktualisasi diri; remaja

\section{ABSTRACT}

Teenagers have great curiosity. This curiosity can cause teenagers become more motivated to be a better person than before. Curiosity in adolescents is also part of the effort to be meaningful not only for themselves but also for others. When a teenager's curiosity is fulfilled, the teenager will be encouraged to actualize himself. This is the part of the existence needs of adolescents. The purpose of this study is to explain the relationship between curiosity and the desire to actualize themselves in adolescents. This research is a quantitative correlational study where the number of participants is 100 people in which uses Self Actualization Activity Inventory (SAAI). This study uses a simple purposive sampling technique. The results showed that there was a relationship between curiosity and self-actualization in adolescents in the school scope $(r=0.581 ; p=0,000)$. This means that the higher the curiosity, the higher the ability of students to actualize themselves. From this study it can be concluded that there is a significant relationship between curiosity and the desire to actualize themselves in adolescents in the scope of the school. Great curiosity causes individuals to try to gather new information and it is important to maximize the potential in themselves so they are able to actualize themselves.

Keywords: curiosity; self-actualization; adolescents

Dipublikasikan Oleh :

UPT Publikasi dan Pengelolaan Jurnal

Universitas Islam Kalimantan Muhammad Arsyad Al-Banjari Banjarmasin 


\section{PENDAHULUAN}

Manusia adalah makhluk sosial yang pada hakikatnya selalu merasa ingin tahu akan segala sesuatu yang berkaitan dengan dirinya. Manusia akan mengumpulkan semua informasi untuk menambah ilmu pengetahuan yang dimilikinya agar bisa mengerti bahkan mengatasi setiap permasalahan yang dihadapinya. Keingintahuan ini akan menyebabkan manusia mempunyai hasrat untuk mengejar, mengarah dan memiliki pengalaman yang mengesankan (Garrosa, Blanco, Carmona \& Moreno, 2016).

Rasa ingin tahu adalah dorongan yang timbul pada seseorang yang sedang belajar dan berkembang. Keinginan tersebut menyebabkan individu menjadi sangat aktif dalam memberi respon pada setiap rangsangan dan kegiatan baru yang bersifat menantang sehingga memerlukan kemampuan berpikir yang kompleks. Kashdan, Rose \& Finchan (2004) menyebutkan bahwa rasa ingin tahu dibedakan menjadi dua yaitu rasa ingin tahu yang bersifat aktif untuk hal-hal yang baru dan rasa ingin tahu untuk mendalami hal yang kompleks. Rasa ingin tahu sangat penting untuk menstimulus individu berinteraksi dengan hal-hal yang baru serta mendapatkan informasi yang tepat dan konkret. Kashdan, Rose \& Finchan (2004) juga menambahkan bahwa rasa ingin tahu akan membuat individu termotivasi untuk menemukan pemahaman yang baru dari sudut pandang berbeda.

Ada beberapa pendekatan yang menimbulkan perasaan ingin tahu seperti yang digambarkan oleh Kashdan, Rose \& Finchan (2004) yaitu: a) meningkatnya perhatian untuk mengamati serta menyesuaikan diri terhadap stimulus yang diterima, b) terdapat manfaat dari proses berpikir dan berperilaku, c) terdapat manfaat dari setiap rangsangan kegiatan yang dilakukan, dan d) terdapat integrasi dari semua pengalaman yang diperoleh dalam proses belajar. Berbagai stimulus yang diberikan memberikan manfaat bagi individu yang mempunyai rasa ingin tahu sehingga akan menjadi lebih mudah untuk aktif memperoleh pengalaman yang baru dalam kehidupannya.

Watson (1988) berpendapat bahwa rasa ingin tahu sangatlah penting untuk dikembangkan agar individu mampu menjaga hubungan dengan lingkungan sosial secara aktif serta memperoleh kepuasan hidup. Terdapat kasus mengenai kecemasan dalam berinteraksi dengan lingkungan sosial merupakan akibat dari ketidakmampuan individu untuk bisa menerima dan menggali informasi yang benar Kashdan \& Roberts (2004). McGillivray, Murayama, \& Castel (2015) memaparkan sebuah studi kasus tentang lemahnya daya ingat dan kemampuan menyimpan informasi akan berdampak pada sulitnya menggali informasi yang sudah diterima sebelumnya. Semakin besar keingintahuan seseorang maka semakin mudah orang tersebut untuk melatih kemampuan daya ingat yang diperlukan dalam menyimpan informasi di otak (Castel 2008).

Rasa ingin tahu menyebabkan seseorang termotivasi untuk menjadi lebih baik dan bermakna bagi dirinya sendiri dan orang lain. Ketika perasaan ingin tahu sudah terpenuhi, maka manusia akan termotivasi untuk mengaktualisasikan dirinya (Arslan, 2017).

Abraham Maslow adalah tokoh yang mencetuskan teori hierarki kebutuhan manusia menjadi lima hierarki, yaitu kebutuhan fisiologis, kebutuhan akan rasa aman, kebutuhan akan cinta dan rasa untuk memiliki, kebutuhan akan harga diri, sertakebutuhan aktualisasi diri. Maslow mendefinsikan kebutuhan aktualisasi diri sebagai kebutuhan yang berasal dari keinginan dalam diri individu untuk berkembang (Bland \&Derobertis, 2017). Pendapat ini juga diperkuat oleh Souza, Adams, \& Fuss (2015) yang medefinisikan aktualisasi diri sebagai proses evolusi seorang individu untuk mewujudkan potensi yang dimilikinya. Neto (2015) menjelaskan bahwa proses aktualisasi diri akan berdampak pada manusia yang mampu mengembangkan potensi dan mempertahankan keyakinan yang dimilikinya.

Abraham Maslow menyatakan bahwa aktualisasi diri dapat dicapai dengan mengeksplorasi segala potensi yang ada dalam diri manusia (Rawat, 2016). Semakin seseorang menggali serta melatih potensi yang dia punya, maka semakin mampu seseorang tersebut mengaktualisasi dirinya.

Seiring dengan pertambahan usia, maka seseorang juga akan mengalami perubahan arah dalam aktualisasi diri. Saat seseorang mencapai usia remaja, maka salah satu tugas perkembangan remaja adalah mengembangkan konsep dan keterampilan intelektual agar memiliki peran sebagai anggota dalam masyarakat (Santrock, 2014). Peran yang dimiliki seorang remaja adalah sebuah pembuktian diri kepada orang lain agar diakui eksistensinya.

Kebutuhan aktualisasi bagi remaja dilakukan dengan cara mengoptimalkan potensi, bakat serta kreativitas dari dalam diri sehingga mereka tidak akan ditolak bahkan mendapatkan pengakuan dari orangorang disekitarnya (Rohman, 2015). Sekolah adalah tempat dimana remaja bebas mengaktualisasikan dirinya. Karena sekolah adalah tempat remaja memperoleh banyak ilmu pengetahuan, pengalaman bersosial dan berkompetisi serta tempat dimana mereka bisa mengembangkan bakat dan potensi dirinya secara optimal dan kreatif.

Rawat (2016) memaparkan bahwa terdapat lima belas karakteristik yang menunjukkan individu memiliki kemampuan untuk mencapai aktualisasi diri, diantaranya yaitu: (1) Mempunyai efisiensi terhadap

Dipublikasikan Oleh : 
persepsi realitas, (2) Mempunyai penerimaan akan diri sendiri, oranglain dan alam, (3) Mempunyai spontanitas, kesederhanaan dan naturalitas, (4) Mampu memusatkan masalah, (5) Memiliki kendali atas kebutuhan privasi, (6) Mempunyai kemandirianakan budaya dan lingkungan, (7) Mampu mengapresiasi, (8), Mempunyai pengalaman, (9) Mempunyai rasa untuk mementingkan kepentingan sosial, (10) Kemampuan untuk melakukan hubungan interpersonal, (11) Mampu menunjukan sikap demokratis, (12) Mampu menyelaraskan antara sarana dantujuan, (13) Mempunya rasa humor yang baik, (14) Memiliki kreativitas, (15) serta Ketahanan akan enkulturasi.

Berdasarkan uraian tersebut, maka peneliti ingin mengetahui bagaimana rasa ingin tahu remaja ditinjau dari keinginan untuk mengaktualiasikan diri dalam ruang lingkup sekolah. Tujuan dari penelitian ini adalah untuk menjelaskan hubungan rasa ingin tahu dengan keinginan untuk mengaktualisasikan diri pada remaja.

\section{METODE PENELITIAN Pendekatan Penelitian}

Penelitian ini merupakan penelitian kuantitatif korelasional product moment (r) karena peneliti ingin mengetahui bagaimana besaran hubungan antara rasa ingin tahu dengan keinginan aktualisasi diri pada remaja. Sugiyono (2012) menyatakan bahwa metode penelitian kuantitatif korelasional adalah metode yang bertujuan untuk mengetahui hubungan antar variabel serta untuk mengetahui tingkat signifikansinya.

\section{Subjek Penelitian}

Populasi dalam penelitian ini adalah remaja siswa Sekolah Menengah Kejuruan (SMK) disalah satu sekolah di kota Palembang yang jumlah populasi siswanya sebanyak 140 siswa. Jumlah sampel pada penelitian ini dengan taraf kepercayaan 95\% berdasarkan tabel Isaac dan Michael berjumlah 100 siswa (Sugiyono, 2012). Teknik pengambilan sampel menggunakan simple purposive sampling dimana peneliti menentukan partisipan berdasarkan pertimbangan jumlah kelas yang telah diketahui sebelumnya.

\section{Variabel dan Instrumen Penelitian}

Penelitian ini menggunakan dua variabel yaitu variabel bebas dan variabel terikat. Variabel bebas dalam penelitian ini adalah rasa ingin tahu sedangkan variabel terikat dalam penelitian ini adalah aktualisasi diri.

Aktualisasi diri adalah kemampuan untuk mengembangkan dan mengoptimalkan potensi dalam diri agar menjadi manusia yang lebih bermakna. Dalam pengukuran variabel aktualisasi diri, peneliti menggunakan Self-Actualization Activity Inventory (SAAI) yang dikembangkan oleh Souza, Adams \& Fuss(2015) yang menjabarkan tiga aspek aktualisasi diri menurut Jones \& Crandal (dalam Souza,Adams \& Fuss, 2015), yaitu: Refleksi diri, Eksplorasi diri dan Kesadaran diri. SAAI adalah skala Likert yang memikiki nilai Cronbach Alpha sebesar 0,939 dan terdiri dari 15 item dengan 4 alternatif jawaban, yaitu: S (Setuju), AS (Agak Setuju), ATS (Agak Tidak Setuju), dan TS (Tidak Setuju). Pada proses penilaian, skor aitem favourable adalah $\mathrm{S}$ (Setuju) $=4$, AS $($ Agak Setuju $)=3$, ATS $($ Agak TidakSetuju $)=2$, dan TS $($ Tidak Setuju $)=1$. Sementara padaaitem unfavourable: $\mathrm{S}$ (Setuju) $=1$, AS $($ Agak Setuju $)=2$, ATS (Agak Tidak Setuju) $=3$, dan TS (Tidak Setuju) $=4$.

Rasa ingin tahu adalah dorongan untuk melakukan pembelajaran, pengamatan, pencarian dan penemuan hal-hal baru. Dalam pengukuran variabel rasa ingin tahu, peneliti mengadaptasi skala Curiosity and Exploration Inventory yang berbentuk skala Likert dan dikembangkan oleh Kashdan, Gallagher, Silvia, Winterstein, Breen, Terhar \& Steger (2009) dengan 5 pilihan respon, yaitu: SS (Sangat Setuju), S (Setuju), N (Netral), TS (Tidak Setuju), dan STS (Sangat Tidak Setuju). Dalam proses penilaian skor nantinya pada item favourable adalah SS (Sangat Setuju $)=5, \mathrm{~S}($ Setuju $)=4, \mathrm{~N}($ Netral $)=3$, TS $($ Tidak Setuju) $=2$, dan STS (Sangat Tidak Setuju) $=1$. Sebaliknya pada item unfavourable: SS (Sangat Setuju) $=1, \mathrm{~S}($ Setuju $)=2, \mathrm{~N}($ Netral $)=3$, TS (Tidak Setuju) $=4$, dan STS (Sangat Tidak Setuju) $=5$. Nilai reliabilitas Curiosity and Exploration Inventory adalah sebesar 0,826, dengan jumlah aitem sebanyak 10 aitem.

\section{Analisis Data}

Penelitian ini menggunakan teknik analisis korelasional product moment (r) dengan bantuan aplikasi perhitungan statistik SPSS versi 25.00.

\section{Hipotesis Penelitian}

Hipotesis dalam penelitian ini adalah terdapat hubungan yang signifikan antara rasa ingin tahu dengan keinginan untuk mengaktualisasikan diri pada remaja dalam ruang lingkup sekolah.

\section{HASIL DAN PEMBAHASAN}

Hasil pengujian analisis data menunjukkan bahwa terdapat hubungan antara rasa ingin tahu dengan aktualisasi diri pada remaja dalam ruang lingkup sekolah $(r=0,581 ; p=0,000)$. Semakin tinggi rasa ingin tahu maka semakin tinggi kemampuan siswa untuk mengaktualisasikan dirinya. 
Tabel 1. Hasil Korelasi Product Moment

\begin{tabular}{ccccccc}
\hline Variabel & Mean & Std.deviation & N & R & Sig & $\mathbf{r}^{2}$ \\
\hline Rasa Ingin Tahu & 35.08 & 6.427 & 100 & 0.581 & 0.000 & 0.34 \\
Aktualisasi Diri & 32.72 & 8.098 & 100 & & & \\
\hline
\end{tabular}

Saran peneliti bagi penelitian selanjutnya

Keinginan untuk mencoba hal yang baru adalah berbeda bagi setiap individu, karena hal ini berhubungan dengan persepsi dan pendapat dari masing-masing individu. Rasa ingin tahu bisa muncul apabila individu memiliki ketertarikan terhadap halhal yang bersifat unik, menantang dan bermanfaat bagi dirinya.

Pada tahapan perkembangan manusia, rasa ingin tahu itu sendiri sangat erat kaitannya dengan pola asuh. Abudulbouh (2016) dalam penelitiannya yang melibatkan 350 siswa sekolah dasar kelas lima dan enam memaparkan bahwa pola asuh demokrasi menyebabkan anak cenderung memiliki keingintahuan yang besar. Pola asuh demokrasi juga memberikan kesempatan bagi individu untuk memilih, menentukan dan menyelesasikan masalahnya dengan mandiri serta mampu bertanggung jawab atas perilakunya. Hurlock (2011) menyatakan bahwa pola asuh demokrasi akan memberikan peluang bagi individu untuk memilih dan menentukan secara mandiri apa yang diinginkan dan dibutuhkan olehnya.

Arslan (2017) menyebutkan bahwa saat perasaan ingin tahu individu telah terpenuhi, maka individu tersebut cenderung memiliki motivasi untuk mengaktualisasikan dirinya. Aktualisasi diri tidak dapat berlangsung apabila tidak ada kebutuhan dari dalam diri serta manfaat bagi diri seorang individu. Kebutuhan tersebut antara lain perolehan status, penghargaan, teman hidup, interaksi dan sebagainya (Krems, Kenrick \& Neel, 2017). Semakin terpenuhinya rasa ingin tahu seorang individu, maka semakin besar keinginan individu tersebut untuk menjadi bermakna tidak hanya bagi dirinya, melainkan juga bagi orang lain. Inilah yang dinamakan kebutuhan aktualiasi diri.

\section{PENUTUP}

Dalam penelitian ini dapat ditarik kesimpulan bahwa terdapat hubungan yang signifikan antara rasa ingin tahu dengan keinginan untuk mengaktualisasikan diri pada remaja dalam ruang lingkup sekolah. Rasa ingin tahu yang besar menyebabkan individu berusaha mengumpulkan informasi baru dan penting untuk memaksimalkan potensi dalam dirinya. Saat rasa ingin tahu tahu telah terpenuhi, maka individu akan termotivasi untuk menjadi individu yang bermakna bagi orang lain.

Dipublikasikan Oleh :

UPT Publikasi dan Pengelolaan Jurnal

Universitas Islam Kalimantan Muhammad Arsyad Al-Banjari Banjarmasin 
Nama Penulis Artikel

Jurnal Bimbingan dan Konseling Ar-Rahman

Volume, Nomor, Tahun Edisi

e-ISSN 2477-6300

Kashdan, T. B, Rose, P., \& Finchan, F.D. (2004). Curiosity and Exploration: Facilitating Positive Subjective Experiences and Personal Growth Opportunities. Journal ofPersonality Assessment, Vol. 82(3), pp. 291-305.

Kashdan, T. B., Gallagher, M. W., Silvia, P. J., Winterstein, B. P., Breen, W. E., Terhar, D., \&Steger, M. F. (2009). The Curiosity and Exploration Inventory-II. Development, factorstructure, and psychometrics. Journal of Research in Personality, Vol 43, pp. 987998

Krems, J. A., Kenrick, D. T., \& Neel, R. (2017). Individual Perceptions of SelfActualization:What Functional Motives Are Linked to Fulfilling One's Full Potential? Personality andSocial Psychology Bulletin, 43(9), 1337-1352. doi: $10.1177 / 0146.1672 .17 .7 .13191$

McGillivray, S., Murayama, K., \& Castel, A. D. (2015). Thirst for Knowledge: The Effects ofCuriosity and Interest on Memory in Younger and Older Adults. Psychology and Aging.Advance online publication.doi:10.1037.a0039801

Neto, M. (2015). Educational motivation meets Maslow : Self- actualisation as contextualdriver Educational motivation meets Maslow: Self-actualisation as contextual, 5(1), 18-27.
Rawat, A. (2016). Assessing the Needs of the Learner through Maslow's Model of SelfActualization. The International Journal of Humanities \& SocialStudies, 4(10), 132-135.

Rohman, Rohman. (2015). Perbedaan Aktualisasi diri Mahasiswa Ditinjau dari Kategori Aktifis dan non-Aktifis. Seminar psikologi \& Kemanusiaan Psychology Forum $U M M($ ISBN: 978-979-796-324-8).

Santrock, J. W. (2014). Educational Psychology (5thEd). Jakarta: Salemba Humanika(ISBN: 978-602-8555-95-1).

Souza, J. F. D., Adams, C. K., \& Fuss, B. (2015). A Pilot Study of Self-Actualization Activity Measurement A Pilot Study of SelfActualization Activity Measurement,(March).

Sugiyono. (2012). Metode Penelitian Kuantitatif, Kualitatif, dan R\&D. Bandung: C.V Alfabeta.

Watson, D. (1988). The Vicissitudes of Mood Measurement: Effects of Varying Descriptors, Time Frames, and Response Formats on Measures of Positive and Negative Affect. Journal ofPersonality and Social Psychology, 55 , pp. $128-141$. 